\title{
Evaluation of Permanent Deformation and Fatigue using Lime Modified Binder
}

\author{
Engr.Haseeb Ali Khan ${ }^{\# 1}$, Dr. Arshad Hussain ${ }^{* 2}$ \\ ${ }^{\# 1}$ Postgraduate Student, National Institute of Transportation, \\ National University of Sciences \& Technology (NUST), Islamabad, Pakistan \\ ${ }^{\# 2}$ Assistant Professor, National Institute of Transportation, \\ National University of Sciences \& Technology (NUST), Islamabad, Pakistan \\ 1 engr.haseeb_official@hotmail.com \\ 2arshad_nit@yahoo.com
}

\begin{abstract}
Hot mix asphalt (HMA) pavements are exposed to repeatedly variations in traffic loads and environmental conditions. When imposed stresses are coupled with environmental actions that are caused owing to frequent traffic loads, a reduction in pavement life occur due to moisture damage. Resultantly, it formed permanent deformation and cracking failures. In order to avert this harm, anti-stripping additive are used to increase adhesion of the aggregate-asphalt interface. In this research, lime -the most common solid anti stripping additive- is used .The study targets to evaluate the permanent deformation and fatigue cracking of lime modified asphalt mixtures through Hamburg Wheel Tracking (HWT) laboratory test and Indirect Tensile Fatigue Test (ITFT). The overall findings concluded that lime modified mixtures shows better results than that of unmodified asphalt mixtures in performance test.
\end{abstract}

Keywords: Asphalt Mixtures, Permanent Deformation, Lime, Hamburg Wheel Tracker Test (HWT), Indirect Tensile Fatigue Test (ITFT)

\section{INTRODUCTION}

The roadway network plays an indispensable role in socio-economic growth of a country, Moreover, with the onset of globalization and burgeoning population, the road congestion increases because of the ownership of vehicle and development of world transportation. This kind of situation increases the volume of traffic, traffic loads and tire pressure. Resultantly, these factors would play a pivotal role in pavement deformation such as the rutting and fatigue cracking. In hot mix asphalt pavements, asphalt is an indispensable part of wearing surface of road structure because it plays pivotal role as a binder so, it has been modified a number of times against its failure [1]. In hot-mix asphalt (HMA) mixtures, owing to distinct stiffening effects of lime, it decrease rut-depth of pavement and also improves bond between aggregate and asphalt [2]. Hydrated lime addition both in wet and dry mode is quantified. In dry mode, $1.5 \%$ lime was added to that of dry aggregate and in wet mode, $20-30 \%$ lime was added to that of asphalt binder weight [3]. Moreover, one of an indispensable benefit of lime is that it has the lowest environmental footprints as compared to simple HMA mixtures [4]. The laboratory examination of lime modified binder concluded that the stability increase with the increases of hydrated lime in the mixture [5]. Furthermore, addition of lime resists the deformation at approximately all temperatures but showed good results at 40 degree temperature [6]. Besides, on the other hand, fatigue cracking is also a problem of concern in the performance and design of hot mix asphalt (HMA) pavements since the hot mix asphalt pavements are being used. Owing to repeated number of traffic loads, structural failure occurs in the pavements that causes fatigue cracks [7].

\section{OBJECTIVES AND SCOPE}

A comprehensive research plan was prepared and following research tasks were outlined. Literature review on the previous researches has been carried out. Specimens were prepared in the laboratory to find optimum asphalt content using superpave gyratory compactor in order to find the volumetric properties of the gyratory samples. Hydrated lime with different percentage including $1 \%, 1.5 \%$ and $2 \%$ is used in samples and volumetric properties were find out. Furthermore, $1.5 \%$ hydrated lime-as significant percentage after determination of volumetric properties- is used in the laboratory samples and performance tests were carried out through Hamburg Wheel Tracker test. Finally results were compared with un-modified samples. Penetration grade 60/70 and superpave $19 \mathrm{~mm}$ and $25 \mathrm{~mm}$ gradation were used. $1.5 \%$ lime was added in the dry state to total weight of dry aggregate. On gyratory compacted samples, Hamburg Wheel Tracker Test was conducted at $40^{\circ} \mathrm{C}$.

On the other hand, the research included the Indirect Tensile Fatigue test on gyratory compacted samples performed on two gradations i.e Superpave $19 \mathrm{~mm}$ and $25 \mathrm{~mm}$ modified with lime. Testing were conducted on two different temperatures i-e $25{ }^{\circ} \mathrm{C}$ and $40^{\circ} \mathrm{C}$ and the load applied on the samples were taken $2500 \mathrm{~N}$. There were two replicate samples tested for each gradation both conventional and unconventional for both the temperatures. 


\section{III.RESEARCH METHODOLOGY}

The research was conducted in three phases. Initially, different aggregate sizes including 0-5mm, 5$10 \mathrm{~mm}, 10-20 \mathrm{~mm}$ were collected through Margalla Quarry. Bitumen source was Attock Refinery Limited (ARL) and penetration grade 60/70 was selected to be used. The reason for selecting the penetration grade 60/70 is that it is the commonly used bitumen grade across Pakistan. After selection of material, next task was to characterize the material according to reference specifications.

For both gradations, the samples were prepared according to superpave mix design manual (SP-2) in order to determine optimum asphalt content. In this way, binder with 3-4.5\% with an interval of 0.5 is used and samples were prepared in gyratory compacter. Each sample weights approximately 4500 gram. The volumetric parameters theoretical maximum specific gravity Gmm, effective specific gravity Gse, Bulk specific gravity Gmb and \%Gmm of prepared specimens were measured, verified in light of Superpave mix design criteria and finally optimum asphalt contents were determined.

In the second phase, for determining the optimum asphalt content, bituminous paving mixes were prepared according to the method explained in Asphalt Institute's Superpave mix design manual (SP-2). HMA samples were prepared using $0 \%, 1 \%, 1.5 \%$ and $2 \%$ of lime. These percentages of lime were added in account of total dry weight of aggregate. The optimum asphalt content for each was determined by repeating the Superpave mix design procedure two times. The volumetric properties of mix including, air voids (Va), voids in mineral aggregates (VMA) and voids filled with asphalt (VFA) were determined using their respective formulae after determination of theoretical maximum specific gravity (Gmm) and bulk specific gravity (Gmb). Theoretical maximum specific gravity $(\mathrm{Gmm})$ and bulk specific gravity $(\mathrm{Gmb})$ were determined in accordance with AASHTO T209 and AASHTO T166 respectively.

The size of the samples prepared in the gyratory compactor used is 6 inch $(150 \mathrm{~mm})$ in diameter and 7 inch $(177.8 \mathrm{~mm})$ in height. After the samples were compacted using the gyratory compactor the samples were left for 24hr to come to the room temperature. Once the samples were at room temperature core cutting machine accompanied by the saw cutting machine was used to core out 4 inch $(100 \mathrm{~mm})$ diameter specimens from the 6 inch $(150 \mathrm{~mm})$ samples. Further the saw cutting machine was used to cut the specimens into the required thickness, at least 1.57 inch $(40 \mathrm{~mm})$ for Indirect Tensile Fatigue Test as instructed in EN $12697-24$ and 150 $\mathrm{mm}$ for wheel tracker test respectively.

In the third phase, the samples were tested in order to find the rut depth and number of cycles to failure of the specified specimen using Hamburg Wheel Tracker (HWT) and Universal Testing Machine (UTM). HWT was performed according to AASHTO T 324-04 standard and the number of passes on the specimens was fixed to 20,000 . Wet mode of wheel tracker device was selected at 40 degree centigrade. Finally the test was run and wheel started moving to and fro on the mounted specimen. One complete to and fro movement of the wheel was taken as 2 passes. The indirect tensile fatigue test was conducted according to EN-12697-24 standard on the cylindrical shaped samples to characterize modified and unmodified HMA mixes under repeated load applied with constant load mode. The cylindrical shaped test samples are subjected to repeated compressive load in the vertical direction. . The testing was performed for $25^{\circ} \mathrm{C}$ and $40^{\circ} \mathrm{C}$ with a load of $2500 \mathrm{~N}$. The samples were tested in Universal Testing Machine UTM 25.

\section{IV.ANALYSIS AND RESULTS}

Test results of Indirect Tensile Fatigue test and wheel tracker tests are presented in this section. Statistical Analysis done on Indirect Tensile Fatigue test in order to obtain the significant factors is also presented in this section.

\section{A. Wheel Tracker Test}

Rutting can be assessed by comparing the rut depths obtained for controlled mixtures of both gradations with the lime-modified mixtures. Result of Hamburg Wheel Tracker test of $19 \mathrm{~mm}$ gradation is shown in figure 1. It is cogent from the figure that for $19 \mathrm{~mm}$ gradation, the rut depth value of modified sample is $3.57 \mathrm{~mm}$ for sample 1 and $3.63 \mathrm{~mm}$ for sample 2 . On taking average of both the values, the average rut depth became $3.6 \mathrm{~mm}$. On the other hand, the values of unmodified samples were $4.27 \mathrm{~mm}$ and $5.02 \mathrm{~mm}$ and their average became $4.645 \mathrm{~mm}$. Conclusively, it showed that average improvement in $19 \mathrm{~mm}$ gradation with $1.5 \%$ lime was notes as $22.04 \%$. The graphical illustrations of $19 \mathrm{~mm}$ gradation test results are shown in figure 1. 


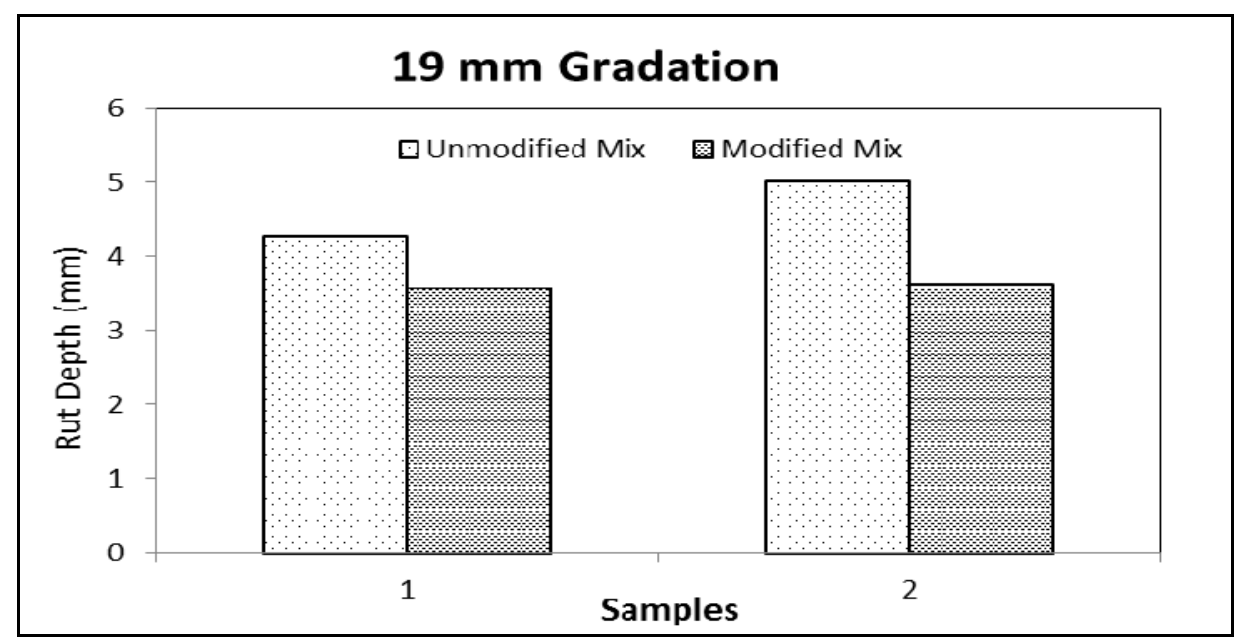

Figure 1: Rut Depth of $19 \mathrm{~mm}$ Gradation at $40^{\circ} \mathrm{C}$

Likewise, results of Hamburg Wheel Tracker test of $25 \mathrm{~mm}$ gradation also showed better results of samples that are modified with lime. For $25 \mathrm{~mm}$ gradation, the rut depth value of modified sample is $1.87 \mathrm{~mm}$ for sample 1 and $1.29 \mathrm{~mm}$ for sample 2 . The average rut depth of modified samples was $1.58 \mathrm{~mm}$. Furthermore, the values of unmodified samples were $3.64 \mathrm{~mm}$ and $2.97 \mathrm{~mm}$ and their average became $3.305 \mathrm{~mm}$. Finally it showed that average improvement in $25 \mathrm{~mm}$ gradation with $1.5 \%$ lime was notes as $52.14 \%$.. The graphical illustrations of $25 \mathrm{~mm}$ gradation test results are shown in figure 2.

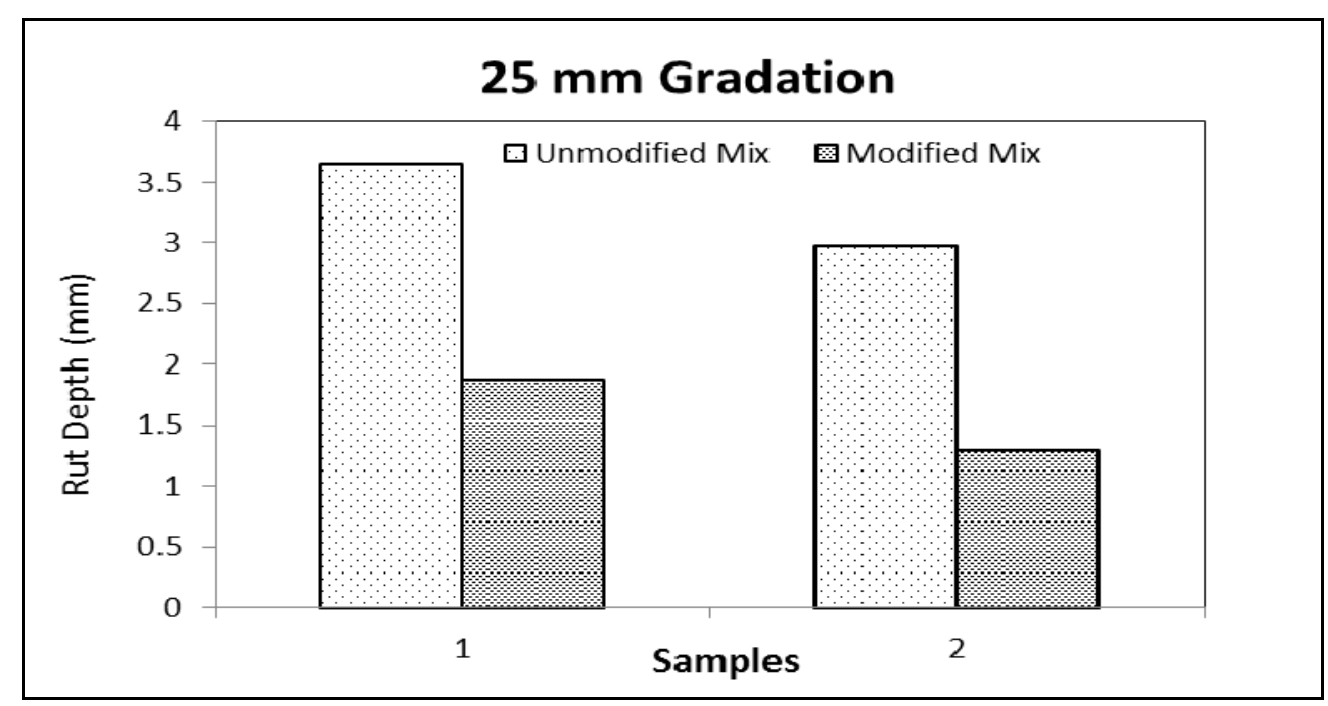

Figure 2: Rut depth of $25 \mathrm{~mm}$ Gradation at $40^{\circ} \mathrm{C}$

\section{B. $\quad$ Indirect Tensile Fatigue Test}

The research included the performance test of Indirect Tensile Fatigue that was performed on two gradations that were modified with lime. Testing were conducted on two different temperatures i-e $25^{\circ} \mathrm{C}$ and $40{ }^{\circ} \mathrm{C}$ and the load applied on the samples were taken 2500N.

It is cogent from the figure 3 that for $19 \mathrm{~mm}$ gradation, the number of cycles to failure of modified sample is 16839 for sample 1 and 15548 for sample 2. On taking average of both the values, the average value became 16193. On the other hand, the values of unmodified samples were 13169 and 14669 and their average became 13919. Conclusively, it showed that average improvement in $19 \mathrm{~mm}$ gradation with $1.5 \%$ lime was notes as 15 $18 \%$. The graphical illustration of $19 \mathrm{~mm}$ gradation at $25^{\circ} \mathrm{C}$ is shown in figure 3. 


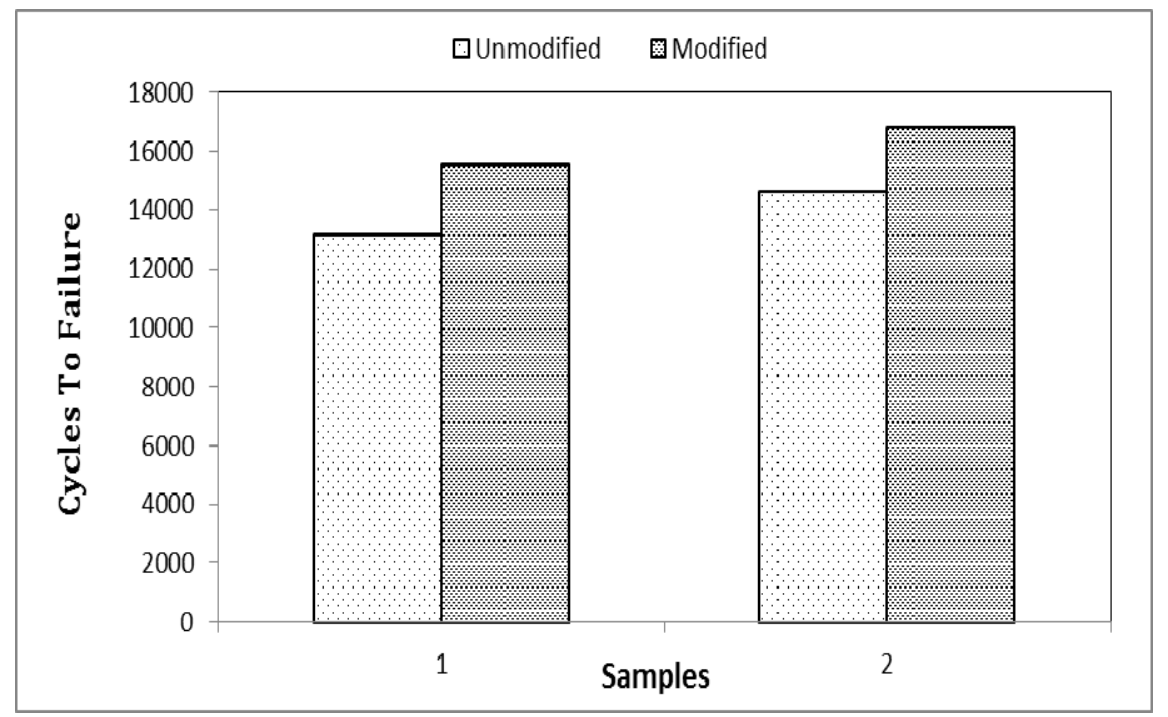

Figure 3: Number of Cycles to failure of $19 \mathrm{~mm}$ Gradation at $25^{\circ} \mathrm{C}$

For 25mm gradation, the number of cycle to failure value of modified sample is 23459 for sample 1 and 20945 for sample 2. The average value of modified samples was 22202. Furthermore, the values of unmodified samples were 19473 and 18979 and their average became 19226. Finally it showed that average improvement in $25 \mathrm{~mm}$ gradation with $1.5 \%$ lime was notes as $10-20 \%$. For $25 \mathrm{~mm}$ gradation at $25^{\circ} \mathrm{C}$, figure 4 illustrates fatigue resistance of modified samples than that of unmodified samples.

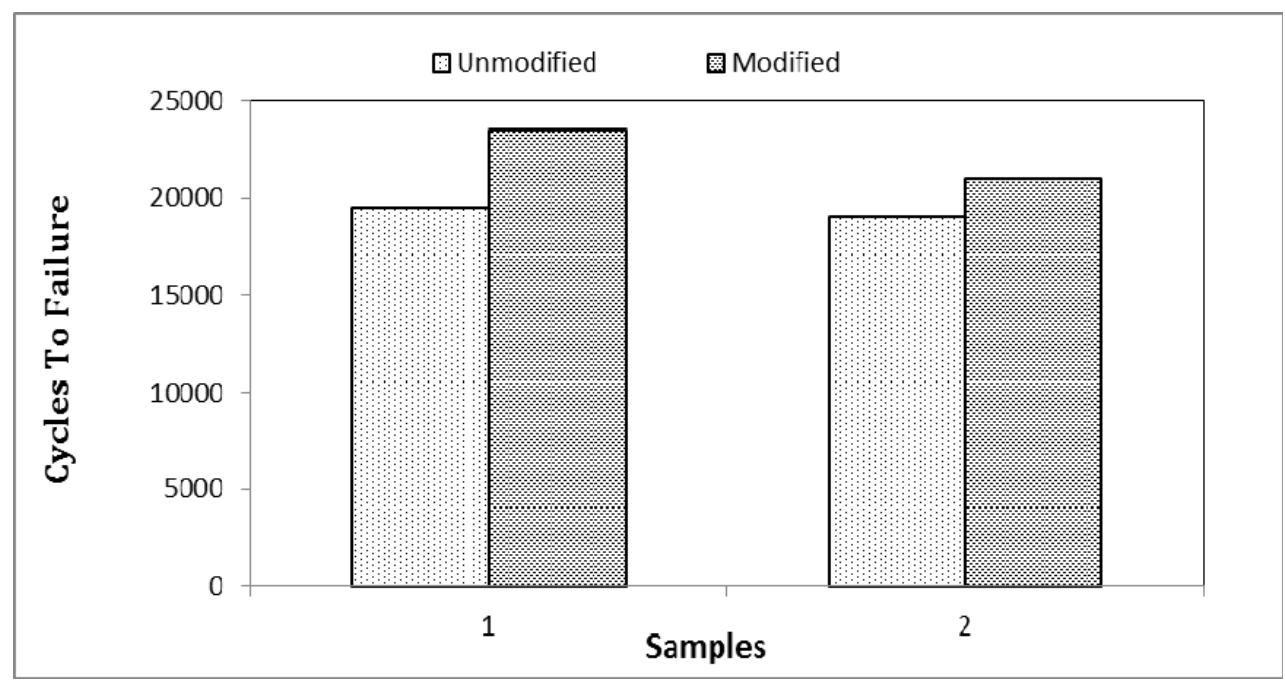

Figure 4: Number of Cycles to failure of $25 \mathrm{~mm}$ Gradation at $25^{\circ} \mathrm{C}$

On the other hand, at $40^{\circ} \mathrm{C}$ for $19 \mathrm{~mm}$ gradation, the number of cycle to failure value of modified sample is 2739 for sample 1 and 2549 for sample 2. The average value of modified samples was 2644. Furthermore, the values of unmodified samples were 2019 and 1979 and their average became 2044. Finally average improvement in $25 \mathrm{~mm}$ gradation with $1.5 \%$ lime was noted as $29-30 \%$ in figure 5 . 


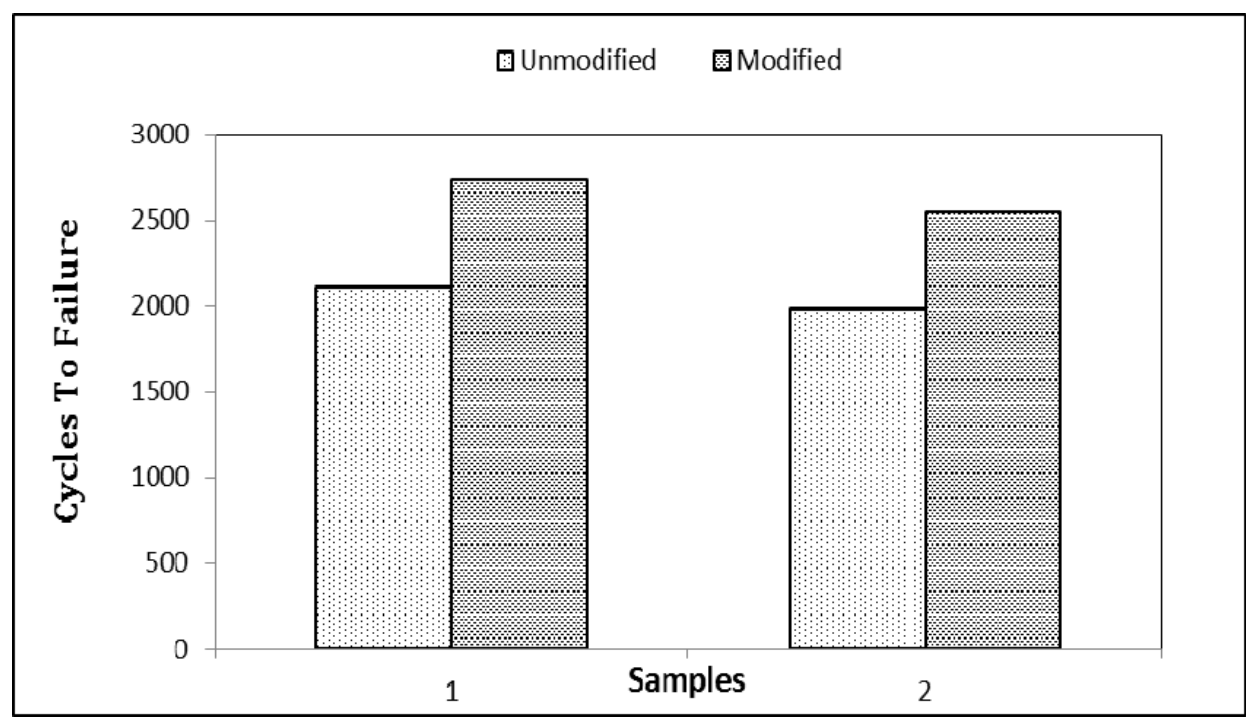

Figure 5: Number of Cycles to failure of $19 \mathrm{~mm}$ Gradation at $40^{\circ} \mathrm{C}$

Similarly at $40^{\circ} \mathrm{C}$ for $25 \mathrm{~mm}$ gradation, the number of cycle to failure value of modified sample is 3879 for sample 1 and 3459 for sample 2. The average value of modified samples was 3669. Figure 6 shows the cycle to failure of $25 \mathrm{~mm}$ gradation at $40^{\circ} \mathrm{C}$. The values of unmodified samples were 3059 and 3019 and their average became 3039. Finally it showed that average improvement in $25 \mathrm{~mm}$ gradation with $1.5 \%$ lime was notes as 15 $27 \%$.

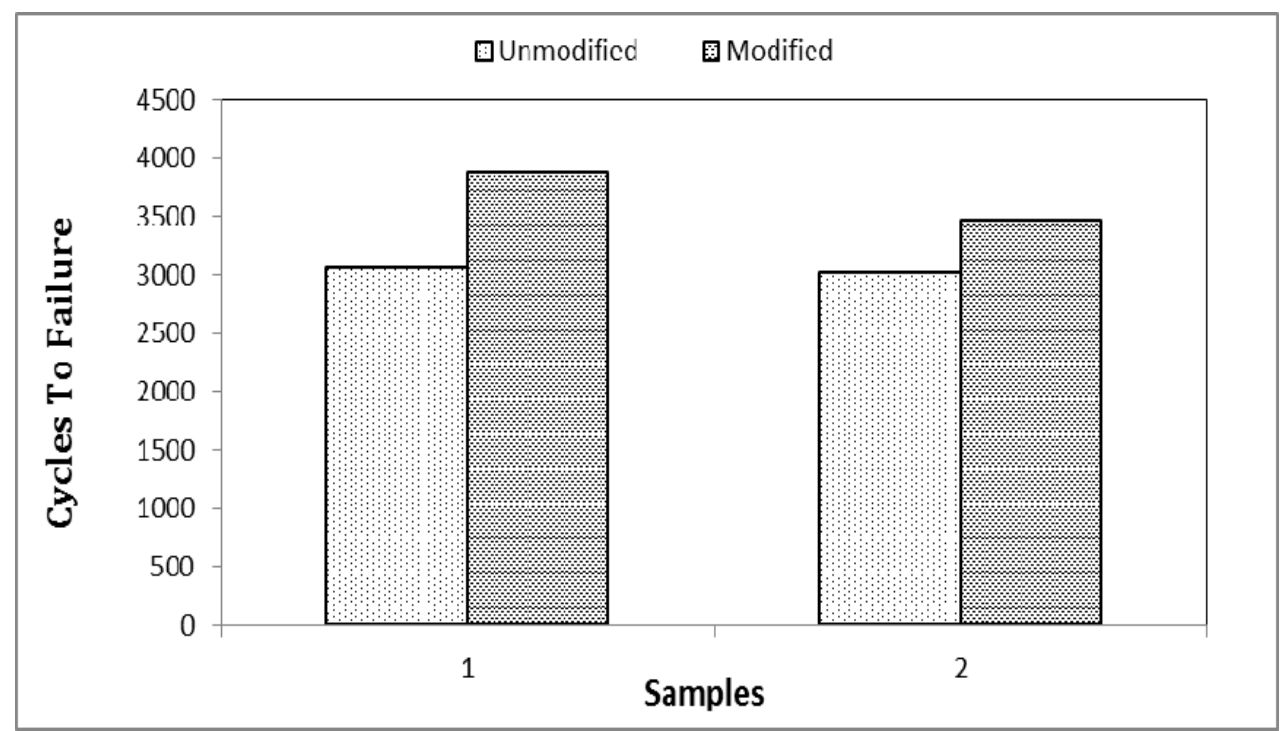

Figure 6: Number of Cycles to failure of $25 \mathrm{~mm}$ Gradation at $40^{\circ} \mathrm{C}$

\section{Statistical Analysis of Indirect Tensile Fatigue Test}

The statistical analysis of ITFT data with and without lime modification was performed by considering three factors i.e. gradation, test temperature and lime percentage each with two levels. Therefore, $2^{3}$ full factorial design of experiment was performed using MINITAB-15 software. Table 1 shows the factors that have been considered in the factorial design with their high and low levels and abbreviations.

Table 1: Factors and their Level for Factorial Design

\begin{tabular}{|c|c|c|c|c|}
\hline Notations & Parameters & Low & High & Units \\
\hline 1 & Gradation & 19 & 25 & $\mathrm{Mm}$ \\
\hline 2 & Temperature & 25 & 40 & ${ }^{\circ} \mathrm{C}$ \\
\hline 3 & Lime & 0 & 1.5 & ${ }^{\%}$ \\
\hline
\end{tabular}




\section{5. $\quad$ Significant Effects}

In terms of Normal probability plot and Pareto plot generated using Minitab 15 software, the factors and interaction of factors, which are most significant and affect fatigue cracking of asphalt mixtures, are also shown. Figure 7 shows the Pareto plot having a reference line with red color which shows that beyond this reference line a significant variable came up and have greater effect on the fatigue cracking. It is obvious that, temperature showed significant result and have greater influence on fatigue cracking of lab prepared mixtures at $5 \%$ significance level. The other plot is the normal probability plot which also shows the significant main effect as shown in figure 8 respectively. In the normal probability plot the factors or interactions away from the reference line are significant at $5 \%$ significance level and the factors which are near the reference line or on the reference line, are insignificant.

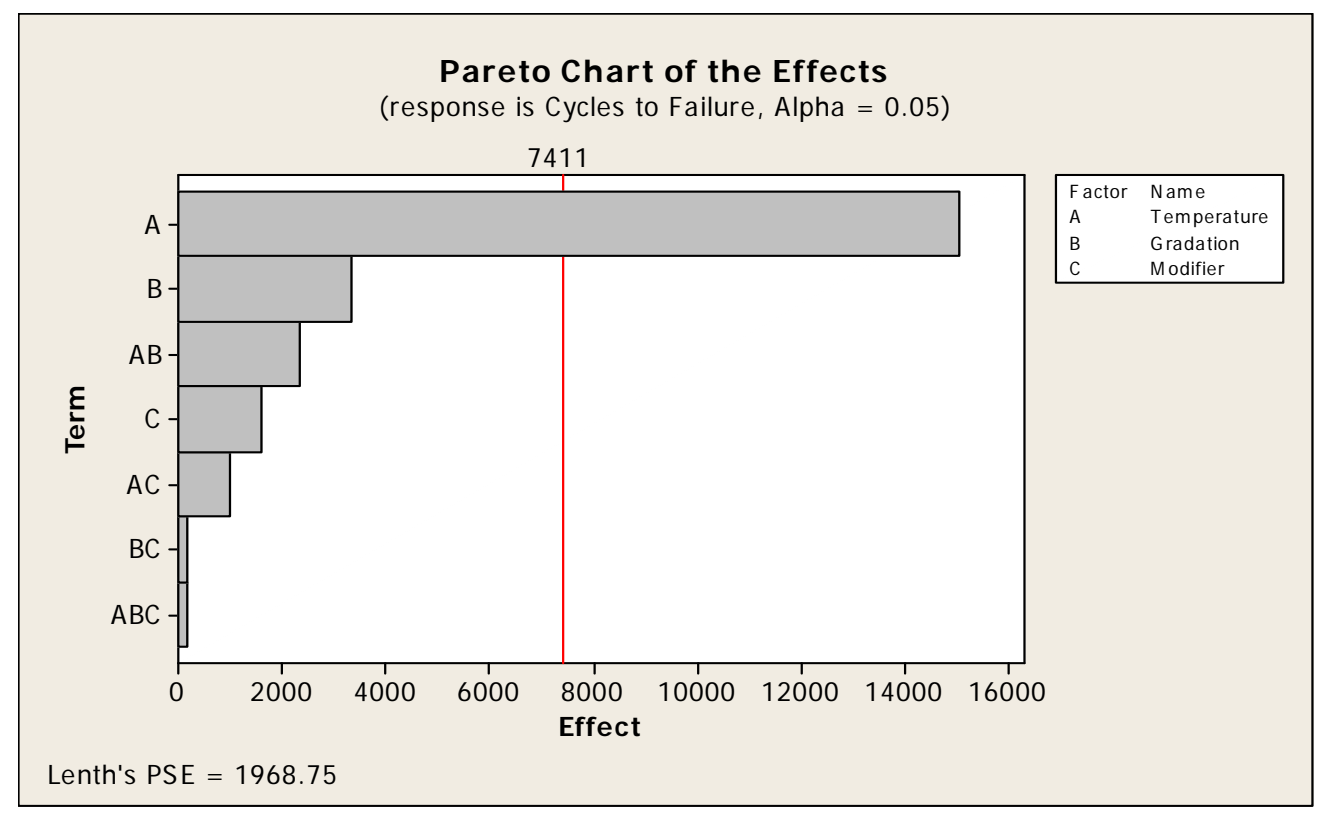

Figure 7: Pareto Chart

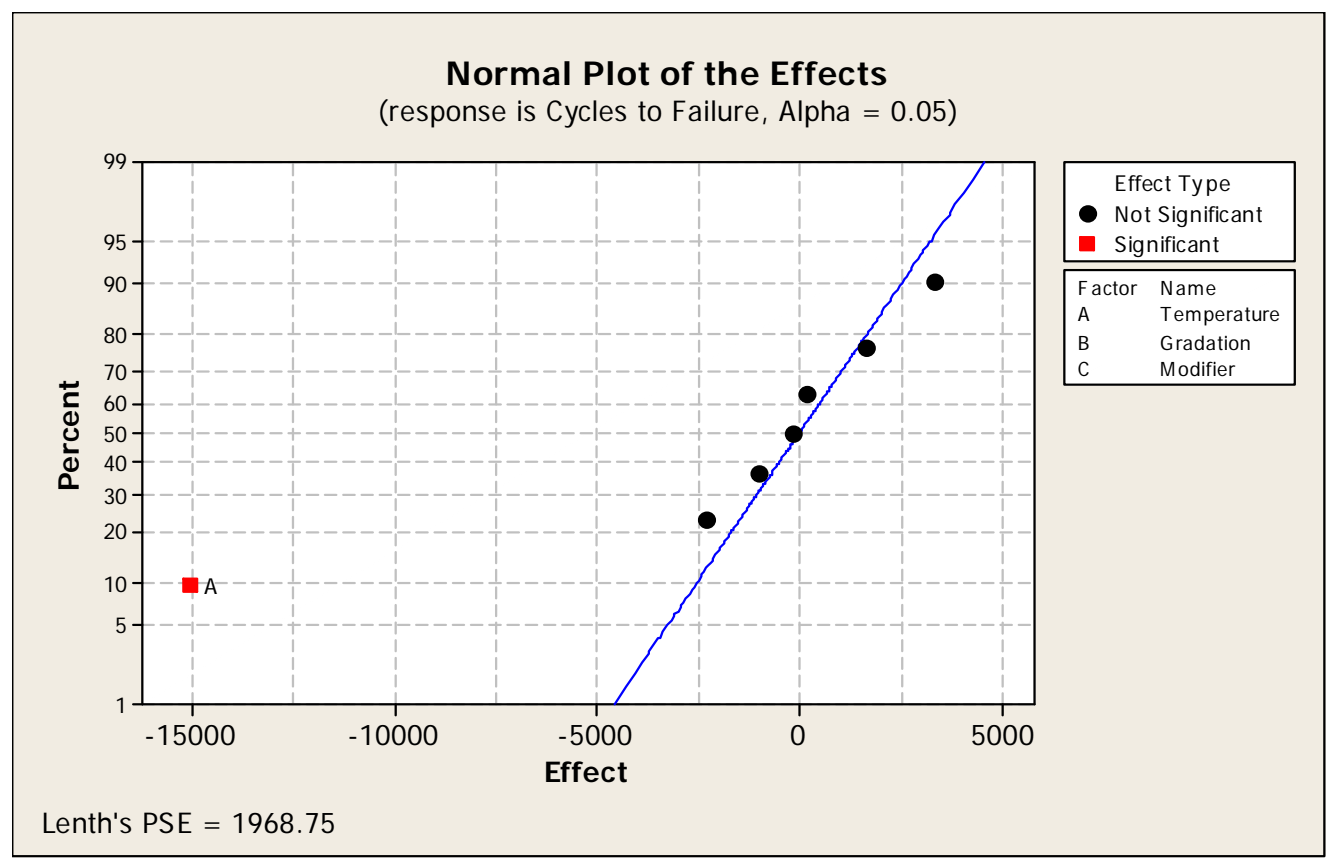

Figure 8: Normal Chart of Samples

\section{6. $\quad$ Main Effect Plots}

The effects of gradation, temperature and lime \%age of lab Prepared specimens are shown in figure 9 respectively. The graph between temperature and fatigue cracking reveals that with increase in temperature the number of cycle to failure decreases. 
The graph between fatigue cracking and gradation indicates direct relationship i.e. the number to cycle failure increases if nominal maximum aggregate size increases.

So from this analysis it is quite obvious that the temperature has greater effect on fatigue cracking as in the below figure, it is clear that the slope of temperature vs number of cycles is greater. Moreover, nominal maximum aggregate size has also greater impact on fatigue cracking as it also showed greater slope. At last, modifier also showed impact on fatigue cracking behavior as its slope in the figure is also liner and inclined that showing effects on fatigue cracking.

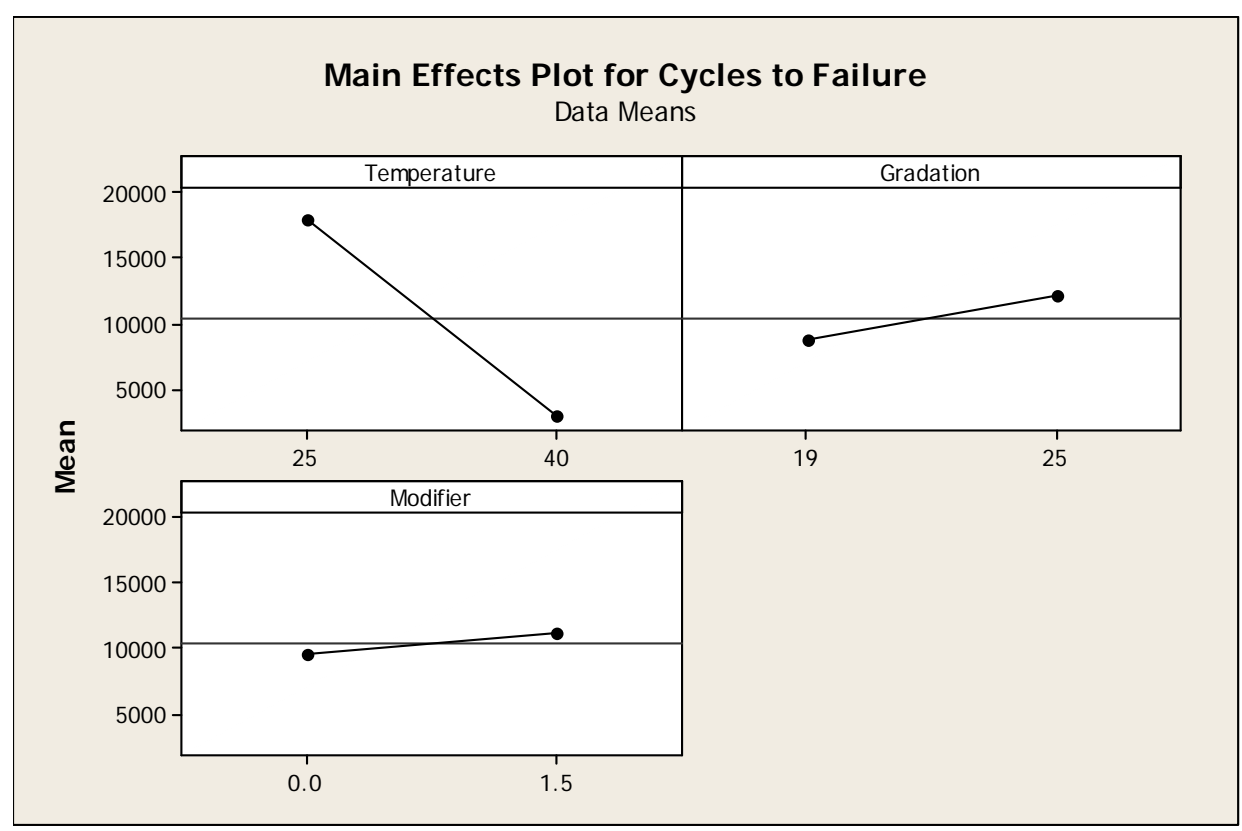

Figure 9: Main Effects Plot

\section{Conclusion}

The conclusions drawn from the analysis of tests as mentioned in chapter 4 are classified as follow:

At $40^{\circ} \mathrm{C}$, the use of $1.5 \%$ lime in asphalt mixtures increases rutting potential to approximately $16-29 \%$ as compared to unmodified asphalt mixtures for $19 \mathrm{~mm}$ gradations.

$>$ For $25 \mathrm{~mm}$ gradation, lime modified binder showed $48-55 \%$ better results than that of unmodified samples at $40^{\circ} \mathrm{C}$.

$>$ With modification of lime the asphalt mixtures shows higher resistance to fatigue cracking at both $25^{\circ} \mathrm{C}$ and $40^{\circ} \mathrm{C}$.

$>$ At $25^{\circ} \mathrm{C}$, improvement in fatigue cracking is observed in $19 \mathrm{~mm}$ gradation in lime modified mixtures whereas $22 \%$ improvement in fatigue cracking is also observed for $25 \mathrm{~mm}$ gradation.

$>$ At $40^{\circ} \mathrm{C}$, improvement in fatigue cracking is observed in $19 \mathrm{~mm}$ gradation in lime modified mixtures whereas $22 \%$ improvement in fatigue cracking is also observed for $25 \mathrm{~mm}$ gradation.

$>$ Statistical analysis shows that temperature is the most significant factor which affects the indirect tensile fatigue test values followed by gradation and lime content.

\section{References}

[1] Muhammad Hussain, Zia ur Rehman, Yousaf Ali. Performance valuation of flexible pavement against rutting. international journal of advanced tructures and geotechnical engineering issn 2319-5347, vol. 04, no. 03, JULY 2015, PP. 1148-1158. IEEE (2006)

[2] Francisco Thiago Sacramento Aragao, Junghun Lee, Yong-Rak Kim, Pravatkarki. Material specific effects of hydrated lime on the properties and performance behavior of asphalt mixtures and asphaltic pavements” Construction and Building Materials 24 538-544 (2010)

[3] Vijay b. kakade, M. Amaranatha Reddy, K. Sudhakar Reddy. "Effect of aging on fatigue performance of hydrated lime modified bituminous mixes” Construction and Building Materials 113 1034-1043 (2016)

[4] T. Schlegel, D. Puiatti, H.-J. Ritter, D. Lesueur, C. Denayer, A. Shtiza. The limits of partial life cycle assessment studies in road construction practices: A case study on the use of hydrated lime in Hot Mix Asphalt. Transportation Research Part D 48 141-160 (2016)

[5] Hanaa Mohammed Mohan, Hayder Abbas Obaid. Laboratory examination for the effect of adding hydrated lime on the moisture damage resistance of asphalt concrete mixtures” Kufa Journal of Engineering (K.J.E)ISSN 2207-5528 Vol. 5, Issue 2, June, (2014)

[6] Yu Wang, Ahmed f. al-Tameemi, Amjadalbayati. "Influence of hydrated lime on the properties and permanent deformation of the asphaltconcrete layers in pavement” Romanian Journal of Transport Infrastructure, Vol.4, No (2015)

[7] Dr. Saad F.Ibrahim et al. An Approach in Evaluating of Flexible Pavement in Permanent Deformation OF Paved AND Unpaved Roads Over Sand Dunes Subgrade Under repeated Loads. Journal of Environment and Earth Science www.iiste.org ISSN 2224-3216 (Paper) ISSN 2225-0948 (Online) Vol.4, No.14, 2014.

[8] AASHTO T 324-04, "Standard Test Method for Hamburg Wheel Track Testing of Compacted Asphalt Mixtures”. (2015). 